\title{
A INFLUÊNCIA DOS TRAÇOS DE PERSONALIDADE NO COMPORTAMENTO FINANCEIRO DOS INDIVÍDUOS: ESTUDO EM UMA CIDADE DO INTERIOR DO ESTADO DO RIO DE JANEIRO
}

\section{TESE}

CAMARGO, Fabiane Kennya de ${ }^{1}$, DOMINGOS, Reinaldo ${ }^{2}$

CAMARGO, Fabiane Kennya de. DOMINGOS, Reinaldo. A influência dos traços de personalidade no comportamento financeiro dos indivíduos: estudo em uma cidade do interior do Estado do Rio de Janeiro. Revista Científica Multidisciplinar Núcleo do Conhecimento. Ano. 06, Ed. 12, Vol. 01, pp. 111-132. Dezembro de 2021. ISSN: 2448-0959, Link de acesso: https://www.nucleodoconhecimento.com.br/administracao/comportamento-financeiro, DOI: $\quad 10.32749 /$ nucleodoconhecimento.com.br/administracao/comportamentofinanceiro

\section{RESUMO}

Este artigo descreve os resultados parciais de uma pesquisa de mestrado, cujo objetivo foi verificar se existe correlação entre os traços de personalidade e o comportamento financeiro das pessoas. A pesquisa buscou responder à seguinte questão-problema: Quais os traços de personalidade que podem estar relacionados ao perfil financeiro de adultos de uma cidade do estado do Rio de Janeiro? Para identificar os traços de personalidade e o perfil financeiro dos 72 participantes, aplicou-se, por meio de uma pesquisa Survey, dois questionários: um com o propósito de diagnosticar se o participante apresenta perfil financeiro Endividado, Equilibrado Financeiramente ou Investidor, e o da teoria Big Five, que é o modelo mais pesquisado e apresenta os traços de personalidade em cinco grandes fatores

\footnotetext{
${ }^{1}$ Mestrado em Administração de Empresas em Educação Financeira; pós-graduação em Educação Financeira, pós-graduação em Estratégia Industrial e Gestão de Negócios, graduação em Ciências Econômicas, Técnico em Contabilidade. ORCID: 0000-0001-7379-5105.

${ }^{2}$ Orientador.
}

RC: 102606

Link de acesso:

https://www.nucleodoconhecimento.com.br/administracao/comportamento-financeiro 
gerais (conscienciosidade, abertura a novas experiências, extroversão, afabilidade e neuroticismo). Os dados foram analisados através do software Survio, sob a técnica de Análise de Conteúdos. Os sujeitos da pesquisa revelaram um perfil financeiro equilibrado com traços de personalidade Conscienciosidade. Entende-se que ao identificarem seu perfil de personalidade as pessoas poderão compreender melhor as suas emoções, seus pontos fortes e fracos, e passarão a fazer escolhas financeiras mais seguras e equilibradas. A identificação do perfil de personalidade pode representar também um avanço significativo no desenho de programas de Educação Financeira visto que durante muito tempo considerou-se que as habilidades numéricas tinham efeito sobre o comportamento financeiro das pessoas, porém estudos identificaram que não basta ter domínio da matemática, haja visto que habilidades não cognitivas como autocontrole, conscienciosidade e otimismo têm impacto significativo nesse tipo de comportamento.

Palavras-chave: Traços de personalidade, Comportamento financeiro, Perfil financeiro.

\section{INTRODUÇÃO}

Em grande parte - senão em todos - os veículos de comunicação e informação, é bastante divulgado o aumento quase incontrolável do nível de endividamento da população, nos últimos tempos. O número de indivíduos e de famílias com dívidas é altíssimo - mesmo anteriormente a este tempo de pandemia trazida pelo coronavírus. Tal constatação tem despertado o interesse dos estudiosos e pesquisadores da área financeira.

Essa realidade tem levado a que pessoas interessadas no tema finanças se preocupem e busquem formas e recursos para contribuir, no sentido de minimizar o problema. Nesse contexto, inserem-se temas como Finanças Comportamentais, Economia Comportamental, alguns dos quais têm se tornado disciplinas ou, até mesmo, ciência. 
Ferreira (2015) menciona diversos estudos os quais evidenciam que as pessoas nem sempre agem conforme planejado (KAHNEMAN, 2002; ARIELY, 2008; NUNES, 2016; THAYLOR, 2011). A psicologia econômica identifica barreiras que impedem as pessoas de colocarem conhecimento em ação e tomar decisões financeiras mais satisfatórias e racionais.

A Economia Comportamental, por seu turno, sugere que as pessoas decidem com base em hábitos, experiência pessoal e regras práticas simplificadas; que aceitam soluções apenas satisfatórias, buscam rapidez no processo decisório, têm dificuldade em equilibrar interesses de curto e longo prazo e são fortemente influenciadas por fatores emocionais e pelos comportamentos dos outros.

Ariely e Kreisler (2019, p. 9-10) atestam uma realidade já percebida e vivenciada por grande parte dos brasileiros: "o dinheiro afeta todos os aspectos da vida moderna, dos orçamentos familiares, à política nacional, das listas de compras às contas de poupança e outros tipos de aplicação". De todas as decisões que os indivíduos precisam tomar, cotidianamente, as que são relacionadas ao dinheiro, talvez, sejam as que exigem mais autocontrole e comprometimento.

Durante muito tempo considerou-se que as habilidades numéricas tinham efeito sobre o comportamento financeiro das pessoas, porém, alguns estudos identificaram que não basta ter domínio da matemática, haja vista que habilidades não cognitivas como autocontrole, conscienciosidade e otimismo têm impacto significativo nesse tipo de comportamento.

Segundo Though "as habilidades cognitivas e não cognitivas estão interligadas, pois certos traços de personalidade ajudam no desenvolvimento de habilidades cognitivas" (apud NUNES, 2016, p. 18). Assim, alude-se que as pessoas têm habilidades individuais que podem determinar o comportamento financeiro.

Nessa direção, considera-se que cada indivíduo é único e possui suas particularidades e, por isso, não se comporta sob o mesmo padrão dos outros, uma percepção que consolidou uma vertente promissora nessa área - a dos traços de 
personalidade. As dimensões da personalidade são exploradas, nesses estudos, cujas abordagens têm servido de auxílio à pesquisa sobre padrões de comportamento no âmbito social e econômico (BORGHANS et al., 2008).

No bojo desse fator de exploração dos traços de personalidade e perfil financeiro, a pesquisa que aqui se descreve pretende responder à seguinte questão problema: Quais os traços de personalidade que podem estar relacionados ao perfil financeiro de adultos de uma cidade do Estado do Rio de Janeiro?

Entende-se que ao identificarem seu perfil de personalidade as pessoas poderão compreender melhor as suas emoções, seus pontos fortes e fracos, e passarão a fazer escolhas financeiras mais seguras e equilibradas. A identificação do perfil de personalidade pode representar também um avanço significativo no desenho de programas de Educação Financeira.

O objetivo do estudo foi correlacionar as características predominantes dos traços de personalidade de acordo com o perfil financeiro de adultos de uma cidade do Estado do Rio de Janeiro identificando, por meio do modelo Cinco Grandes Fatores (Big Five), o perfil de personalidade dos sujeitos participantes pesquisa, bem como o perfil financeiro desses sujeitos, por meio do teste da metodologia DSOP[3].

\section{REFERENCIAL TEÓRICO}

\subsection{ECONOMIA COMPORTAMENTAL}

Trata-se de uma disciplina relativamente nova, que tem origem na incorporação, via economia, de estudos e descobertas empíricas no campo da psicologia, da neurociência e de outras ciências sociais. O ponto de partida tem sido uma crítica à abordagem tradicional sobre economia, que se apoia no conceito de homo economicus - o homem toma decisões de modo racional, ponderado, centrado no interesse pessoal e com capacidade ilimitada de processar informações. A economia tradicional considera que o mercado ou o próprio processo de evolução são capazes 
de solucionar erros de decisão provenientes de uma racionalidade limitada, conforme consideram Ávila e Bianchi (2018)[4].

Simon (1947), um dos expoentes em relação a esses estudos, defendia a utilização de mecanismos cognitivos para se analisar o comportamento dos indivíduos. O autor empregou o termo "racionalidade limitada" como referência à tese de que a mente humana não dá conta de resolver questões que estejam dentro dos padrões propostos de comportamento racional sobre economia, tendo em vista as limitações cognitivas do ser humano. Nesse sentido, esse autor se junta a Kahneman e Tversky (1979) e Camerer (1999; 2005), como autores que vêm definindo e consolidando o campo da Economia Comportamental.

De acordo com Milanez (2003, p. 13), essa linha de pesquisa ganhou enorme audiência entre economistas, e, hoje, vários de seus mentores atuam nas principais escolas de Economia e Negócios dos Estados Unidos". O autor acrescenta que "em várias delas existem cursos sobre behavioral economics", além de diversos artigos já publicados sobre behavioral finance. Daniel Kahneman possui alguns trabalhos sobre comportamento econômico, uma linha de pensamento que tem ganhado cada vez mais espaço no meio acadêmico.

Para Thaler e Mullainathan (2000), "a Economia Comportamental estuda como a combinação de conceitos econômicos, sociológicos e psicológicos pode explicar o que acontece na vida econômica real (apud MILANEZ, 2003, p. 15)", uma vez que as pessoas têm limitações, em relação ao tratamento racional de suas finanças.

Nota-se que, de acordo com a teoria tradicional de economia comportamental, as pessoas, de modo geral, agem, financeiramente, com base na racionalidade ilimitada, ou seja, tomam decisões sob a visão do que esperam, em termos de utilidade; desse modo, dentro da teoria neoclássica, os aspectos psicológicos são desconsiderados. Economia Comportamental constitui uma abordagem mais recente que surgiu estimulada pelas transformações econômicas e pela evolução financeira. Esses fatores provocaram determinados comportamentos para cujas explicações as 
teorias financeiras tradicionais não mais se mostraram suficientes: um dos motivos está no fato de essas teorias, em grande parte, desconsiderarem a cognição humana, conforme explicitado por Yoshinaga et al. (2008). A Economia Comportamental (ou Finanças Comportamentais) se alicerçou na concepção de que as decisões são influenciadas por uma série de fatores comportamentais e limites de arbitragem (MILANEZ, 2003) e, que por esse motivo, não podem ser consideradas totalmente racionais.

Os estudos nessa área têm base nos traços de personalidade, em que se exploram as dimensões da personalidade. De certo modo, esses estudos têm trazido maior compreensão dos padrões de comportamento, das decisões e resultados no âmbito social e econômico (BORGHANS et al., 2008).

\subsection{TRAÇOS DE PERSONALIDADE}

Trata-se de um assunto explorado dentro do tema da pesquisa, tendo em vista que 0 meio em que o indivíduo vive influencia o seu comportamento. Por exemplo, os conceitos primários referentes às questões financeiras são formados na infância e se consolidam durante a vida, à medida em que hábitos e atitudes são desenvolvidos para satisfazerem necessidades e desejos.

A teoria dos traços de personalidade diz respeito às habilidades não cognitivas, haja vista que é utilizada para identificar como as pessoas agem em diferentes contextos ao longo da vida; parte-se do pressuposto de que a personalidade "é uma hierarquia de traços caracterizados por tendências duradouras que constituem formas de comportamento em diferentes situações" (PACHECO; CAMPARA; COSTA JR., 2018, p. 56).

Essa constatação ratifica a complexidade de mensurar os traços de personalidade, que foi amenizada com o surgimento do Modelo dos Cinco Grandes Fatores (Big Five Personality Traits), o qual vem sendo utilizado por descrever as dimensões humanas de forma consistente e replicável [...] Vale ressaltar que a estrutura do Big Five não determina que existam apenas cinco diferentes traços de personalidade, mas sim, que são dimensões amplamente

RC: 102606

Link de acesso:

https://www.nucleodoconhecimento.com.br/administracao/comportamento-financeiro 
representativas incluindo características distintas (PACHECO; CAMPARA; COSTA JR., 2018, p. 56).

Entender a Teoria dos Traços de Personalidade requer que se compreenda o que vem a ser personalidade e como ela se forma em uma pessoa. Basicamente, "personalidade são as características que tornam uma pessoa única. Essas características podem ser os traços, defeitos, qualidades e peculiaridades que a tornam diferente de todos os outros"; no âmbito da psicologia, "são as diferenças que o indivíduo possui nos padrões que caracterizam os pensamentos, comportamentos e sensações" (EHLKE, 2019, s. p.).

De acordo com Silva e Nakano (2011, p. 51), a palavra personalidade faz referência aos padrões de comportamento e às atitudes que são típicas dos indivíduos, relativamente constantes e estáveis, razão por que os traços de personalidade diferem de um indivíduo para o outro.

Esses mesmos autores fazem referência ao conceito de Allport (1966), que caracteriza a personalidade como "a organização dinâmica, no indivíduo, dos sistemas psicofísicos que determinam seu comportamento e seus pensamentos característicos". Referem-se, ainda, a Trentini et al. (2009), para os quais "a personalidade se referiria às características dos indivíduos, sendo única e o distinguindo dos demais a partir de padrões consistentes de sentimentos, pensamentos e comportamentos" (apud SILVA; NAKANO, 2011, p. 52).

Contudo, independentemente dos conceitos, todos admitem que é a personalidade que torna as pessoas únicas, que as diferencia e que tem grande importância e impactos na vida das pessoas.

Um dos modelos mais difundidos, dentro da teoria dos traços, é o modelo dos Cinco Grandes Fatores da personalidade, também conhecido como Big Five, considerado como "uma teoria explicativa e preditiva da personalidade humana e de suas relações com a conduta", conforme Silva e Nakano (2011, p. 52) registram. Esse modelo tornou-se tão relevante que até 2006 já se contavam, em diversas bases de 
dados internacionais, 1.672 publicações referentes ao modelo, conforme relatam as mesmas autoras.

A palavra personalidade tem origem no vocábulo latino "persona", atribuído à máscara utilizada por atores em peças teatrais. Com base nesse sentido, é fácil entender a razão por que passou a se referir à aparência externa, a face que se torna visível e pública quando as pessoas se apresentam (SCHULTZE; SCHULTZE, 2016).

São inúmeros os traços de personalidade que existem, tendo vista que cada ser humano é único e comporta-se de maneira específica e particular. Com base no modelo dos Cinco Grandes Fatores, é possível observar o modo como uma pessoa reage, quando confrontada, como se relaciona com os outros e como enxerga 0 mundo, peculiaridades absolutamente inerentes a cada indivíduo (BORGHANS et al., 2008).

Esses mesmos autores explicitam os cinco grandes traços de personalidade: 1) Neuroticismo (mede a instabilidade emocional da personalidade do indivíduo); 2) Extroversão (mede o nível de energia, a sensação de bem-estar, as habilidades nas relações interpessoais, a necessidade de atenção e o grau de interação social); 3) Abertura à experiência (mede a complexidade do indivíduo e a percepção que a pessoa tem da própria capacidade); 4) Afabilidade, também conhecido como Socialização (mede a necessidade de a pessoa ser agradável e harmoniosa em suas relações); 5) Conscienciosidade (mede o grau de concentração do indivíduo, descreve o controle de impulsos e se a pessoa está disposta a cumprir regras, padrões e normas) (BORGHANS et al., 2008).

\section{METODOLOGIA}

A pesquisa definiu-se como descritiva, do ponto de vista dos seus objetivos. O estudo, predominantemente qualitativo, previu, contudo, a tabulação em percentuais dos dados obtidos no instrumento de verificação, o questionário. 
A etapa inicial passou pelo levantamento bibliográfico, tanto de produções em bancos de dados científicos quanto na gama de literatura e autores que tratam das temáticas que envolvem a pesquisa.

O instrumento de coleta de dados utilizado foi um questionário, aplicado eletronicamente em 11 de agosto de 2020 a 25 de agosto de 2020, via site de pesquisa http://www.survio.com/br. Trata-se de um sistema moderno de pesquisa on-line que oferece, como tantos outros sites dessa modalidade, uma forma eficaz para a preparação de questionários, coleta, análise de dados e compartilhamento dos resultados.

No relatório do programa constam 327 visitas, das quais houve apenas 84 respostas registradas. Desse número de respostas, somente 72 questionários puderam, por questões técnicas, constituir a amostra. $O$ convite para participação na pesquisa foi enviado, aleatoriamente, via aplicativo WhatsApp.

Aos sujeitos da pesquisa foi enviado, via aplicativo, um questionário com 27 questões fechadas, organizado em três blocos de perguntas: a) perfil dos respondentes; b) 10 perguntas dos Cinco Grande Fatores - Big Five -, para identificação dos traços de personalidade dos participantes; c) 10 perguntas a fim de se reconhecer o perfil financeiro dos sujeitos participantes da pesquisa.

Para a análise descritiva dos fatores investigados (traços de personalidade e conhecimento financeiro) utilizou-se a técnica de Análise de Conteúdo, cuja aplicação prevê duas funções básicas que, entretanto, se complementam. São elas: a) verificação de hipóteses e/ou questões, ou seja, com essa técnica podem-se encontrar respostas para as questões formuladas, além de confirmar (ou não) hipóteses levantadas e b) descoberta do que está por trás do material coletado (MINAYO, 2001).

A cronologia dessa análise seguiu as seguintes fases: pré-análise dos dados, exploração do material e tratamento dos resultados, inferências e interpretação. $\mathrm{Na}$ primeira fase, organizou-se o material que seria analisado, definindo-se, à luz dos 
objetivos e problemática do estudo, as unidades significativas e as categorias, que ficaram assim definidas: traços de personalidade; perfil financeiro; a interação dos traços de personalidade e perfil financeiro; o conhecimento financeiro dos participantes. Em seguida, aplicou-se o que foi definido na fase anterior, o que exigiu várias leituras do mesmo material.

Seguiu-se, então, a terceira fase, na qual, com base em princípios quantitativos, tentou-se desvendar conteúdos/dados subjacente ao que estava manifesto no instrumento de investigação, gerando, dessa forma, os quadros e tabelas representativos desses dados.

\section{RESULTADOS DA PESQUISA}

Inicialmente, como é frequente em pesquisas, buscou-se identificar o perfil sociodemográfico dos participantes que formaram a amostra com a qual se trabalhou.

O que se evidenciou, relativamente ao perfil geral dos 72 participantes, é que esse universo se compõe, predominantemente, de indivíduos do sexo feminino $(65 \%)$ e com idade compreendida entre 41 e 65 anos, conquanto se tenha verificado, também, um percentual significativo de participantes com idade entre 25 e 40 anos.

Com relação à escolaridade, o nível mais representativo é de graduação, seguido da Pós-graduação. Dessa população, 57,80\% têm renda mensal de $R \$ 2.005,00$ a $R \$$ $8.640,00$.

\subsection{OS TRAÇOS DE PERSONALIDADE}

Como já referido neste estudo, trata-se do teste de personalidade mais utilizado em pesquisas científicas, o teste é aplicado para medir cinco dimensões ou traços de personalidade. 
Parte-se do princípio de que a abordagem característica da personalidade é formada pela combinação de vários traços, formando uma identidade única para cada indivíduo. O modelo Big Five Inventory-10, adotado para este estudo, resume um conjunto complexo de diferenças individuais em cinco traços básicos universais: Extroversão, Afabilidade, Conscienciosidade, Neuroticismo e Abertura (a experiências). O foco é, desse modo, a identificação e mensuração de todas essas características da personalidade individual.

Esse modelo tem sido bastante empregado na Psicologia Cognitiva e CognitivoComportamental, haja vista que fornece um panorama geral da personalidade humana, tomando como base 4 a 5 subcategorias, dependendo do autor, conforme informa o site do IDRlabs 2020.

Utilizaram-se, tal como é mais frequente, cinco níveis de respostas, quais sejam: 1) Discordo totalmente; 2) Discordo; 3) Não concordo, nem discordo (indiferente, portanto); 4) Concordo; e 5) Concordo totalmente. Para cada dimensão há duas proposições (marcadores), perfazendo o total de 10; por exemplo, para o traço Extrovertido, as proposições são "é reservado/é sociável, extrovertido".

Para a análise que aqui se descreve, trabalhou-se com uma escala cuja base tomou-se da escala Likert (1932). As respostas são analisadas de acordo com o peso das alternativas de respostas, assim: "discordo totalmente" = peso 1; "discordo" = peso 2; "não concordo/nem discordo" = peso 3; "concordo " = peso 4; "concordo totalmente" = peso 5 - para os itens que caracterizam cada traço.

Para os itens que não correspondem às características de cada traço, o peso é distribuído assim: "discordo totalmente" = peso 5 ; "discordo" = peso 4; "não concordo/nem discordo" = peso 3; "concordo " = peso 2; "concordo totalmente" = peso 1. Veja-se, no Quadro 1, como os participantes da pesquisa se posicionaram em relação às proposições. 
Quadro 1 - Frequência das respostas do teste traços de personalidade

\begin{tabular}{|c|c|c|c|c|c|c|}
\hline DIMENSÃO & $\begin{array}{l}\text { MARCADOR } \\
\text { ES }\end{array}$ & $\begin{array}{l}\text { Discordo } \\
\text { totalmen } \\
\text { te }\end{array}$ & $\begin{array}{l}\text { Discor } \\
\text { do }\end{array}$ & $\begin{array}{l}\text { Não } \\
\text { concor } \\
\text { do nem } \\
\text { discord } \\
\text { o }\end{array}$ & $\begin{array}{l}\text { Concor } \\
\text { do }\end{array}$ & $\begin{array}{l}\text { Concord } \\
\text { o } \\
\text { totalmen } \\
\text { te }\end{array}$ \\
\hline & & $\mathbf{F}$ & $\mathbf{F}$ & $\mathbf{F}$ & $\mathbf{F}$ & $\mathbf{F}$ \\
\hline \multirow[t]{2}{*}{ Extroversão } & É reservado* & 1 & 14 & 17 & 37 & 3 \\
\hline & $\begin{array}{l}\text { É sociável, } \\
\text { extrovertido** }\end{array}$ & 2 & 3 & 8 & 46 & 13 \\
\hline \multirow[t]{2}{*}{ Afabilidade } & $\begin{array}{l}\text { Geralmente } \\
\text { confia nas } \\
\text { pessoas }^{* *}\end{array}$ & 2 & 13 & 23 & 32 & 2 \\
\hline & $\begin{array}{l}\text { Tende a ser } \\
\text { crítico com } \\
\text { os outros } \\
\text { (encontrar } \\
\text { defeitos) * }\end{array}$ & 4 & 18 & 24 & 21 & 5 \\
\hline \multirow[t]{2}{*}{$\begin{array}{l}\text { Conscienciosid } \\
\text { ade }\end{array}$} & $\begin{array}{l}\text { Tende a ser } \\
\text { preguiçoso* }\end{array}$ & 18 & 35 & 13 & 6 & 0 \\
\hline & $\begin{array}{l}\text { Insiste até } \\
\text { concluir a } \\
\text { tarefa ou } \\
\text { trabalho** }\end{array}$ & 0 & 3 & 6 & 46 & 17 \\
\hline \multirow[t]{2}{*}{ Neurotiscismo } & $\begin{array}{l}\text { É relaxado, } \\
\text { controla bem } \\
\text { o estresse* }\end{array}$ & 5 & 19 & 22 & 26 & 0 \\
\hline & $\begin{array}{l}\text { Fica nervoso } \\
\text { facilmente }^{\star *}\end{array}$ & 4 & 28 & 19 & 18 & 3 \\
\hline Abertura & Tem poucos & 10 & 24 & 17 & 17 & 4 \\
\hline
\end{tabular}

RC: 102606

Link de acesso:

https://www.nucleodoconhecimento.com.br/administracao/comportamento-financeiro 
experiência

\begin{tabular}{|c|c|}
\hline $\begin{array}{l}\text { intere } \\
\text { artíst }\end{array}$ & \\
\hline $\begin{array}{l}\text { Tem } \\
\text { imagi } \\
\text { fértil* }\end{array}$ & $\begin{array}{l}\text { uma } \\
\text { zão }\end{array}$ \\
\hline
\end{tabular}

\begin{tabular}{|l|l|l|}
\hline 9 & 11 & 37 \\
\hline & &
\end{tabular}

37

Fonte: Dados da pesquisa; adaptado do modelo de Pacheco (2017, p. 64). * Marcadores considerados não característicos do traço correspondente. ** Marcadores considerados característicos do traço correspondente.

No Quadro 2, a seguir, registram-se os números representativos da soma e respectivo total dos itens marcados pelos participantes da pesquisa, referentes ao teste dos traços de personalidade.

Quadro 2 - Resultado da soma dos marcadores e os respectivos totais

\begin{tabular}{|l|l|l|l|}
\hline DIMENSÃO & MARCADORES & Somatório & Total \\
\hline Extroversão & É reservado & 189 & 470 \\
& É sociável, extrovertido & 281 & \\
\hline Afabilidade & Geralmente confia nas pessoas & 235 & 446 \\
\hline \multirow{2}{*}{ Conscienciosidade } & Geralmente confia nas pessoas & 211 & \\
\hline \multirow{2}{*}{ Neuroticismo } & Tende a ser preguiçoso & 281 & 574 \\
& Insiste até concluir a tarefa ou trabalho & 293 & \\
\hline Abertura & É relaxado, controla bem o estresse & 219 & 423 \\
\hline & Fica nervoso facilmente & 204 & \\
\hline & Tem poucos interesses artísticos & 235 & 505 \\
\hline & Tem uma imaginação fértil & 270 & \\
\hline
\end{tabular}

Fonte: Dados da pesquisa; adaptado do modelo de Pacheco (2017, p. 62).

RC: 102606

Link de acesso:

https://www.nucleodoconhecimento.com.br/administracao/comportamento-financeiro 
Com base no que foi apresentado na Figura 4, tem-se, então, em ordem decrescente, os traços que levaram à identificação do perfil de personalidade correspondente aos 72 participantes da pesquisa, calculados de acordo com os respectivos pesos correspondentes ao critério estabelecido e já referido anteriormente. Confira-se no Quadro 3.

Quadro 3 - Resultado final do perfil de personalidade

\begin{tabular}{|l|l|}
\hline DIMENSÃO & RESULTADO CORRESPONDENTE AO CÁLCULO FINAL \\
\hline Conscienciosidade & 574 \\
\hline Abertura & 505 \\
\hline Extroversão & 470 \\
\hline Afabilidade & 446 \\
\hline Neuroticismo & 423 \\
\hline
\end{tabular}

Fonte: Dados da pesquisa.

Verifica-se que o cálculo bastante superior aos outros é o que corresponde à dimensão Conscienciosidade, um traço que é característico de indivíduos determinados, que insistem até concluir a tarefa ou trabalho. Considere-se que o segundo maior resultado incide no traço a Abertura à Experiência - um traço característico de indivíduos que vivem em constante busca de novas experiências, sensações e atividades intelectuais diversas.

Com esse resultado, com base nos dados coletados no instrumento de pesquisa e nos cálculos da frequência das respostas, identifica-se um perfil de personalidade, dos 72 participantes, de conscienciosidade, uma dimensão que, no estudo dos traços de personalidade, incide em atitudes que revelam responsabilidade, autodisciplina, controle dos impulsos, além de manifestarem determinação, organização, produtividade, entre outras características afins (SIMÕES, 2016; BORGHANS et al., 2008; SILVA; NAKANO, 2011; PACHECO; CAMPARA; COSTA JR,. 2018). 
Considera-se pertinente, diante da leitura, interpretação e análise desses dados, registrar o que Melo $(2015$, p. 1) esclarece:

Segundo Srivastava, a estrutura do Big Five deriva de análises probabilísticas a respeito de quais traços tendem a ocorrer juntos nas descrições que as pessoas fazem de si mesmas ou de outras pessoas. No entanto, ainda que trate de dimensões importantes da personalidade, é insuficiente para compreender todos os aspectos. Cabe destacar que mesmo o mais amplo e profundo perfil dos traços de personalidade de uma pessoa é incapaz de dar conta de toda a complexidade de sua personalidade. Portanto, um inventário de apenas 10 perguntas, como o apresentado nesta pesquisa, pretende levantar apenas aspectos gerais da personalidade, na tentativa de verificar somente se existe alguma possível correlação com o grau de educação financeira.

Com esse entendimento, menciona-se que foi possível reconhecer o perfil de Conscienciosidade como o mais pontuado, o predominante, seguido do traço Abertura à Experiência. Contudo, o que se pôde verificar pelos resultados numéricos, é que os cinco traços do perfil de personalidade estão presentes nos 72 sujeitos que constituíram a população do estudo, o que de certa forma corrobora o que foi exposto acima por Melo (2015).

Ao se analisarem os traços de personalidade pretende-se enriquecer o estudo sobre o comportamento financeiro das pessoas, pois o pressuposto é de que elas tendem a tomar decisões em eventos incertos, e o modelo permite analisar, inclusive, como elas processam as informações. A tomada de decisões em situações de incerteza, de acordo com Borghans et al. (2008), alarga a possibilidade de se estudar a personalidade para variáveis econômicas.

Há uma pesquisa, divulgada pelo Banco de Compensações Internacionais (BIS) em maio de 2017 - "Understanding the Determinants of Financial Outcomes and Choices: The Role of Noncognitive Abilities"[5] -, cujo objetivo foi entender a ligação que existe entre as habilidades não cognitivas, bem-estar financeiro e a tomada de decisões financeiras. O estudo, na sua versão original, com o propósito de compreender, também, acerca de comportamento financeiro, apontou que "as habilidades não cognitivas influenciam as escolhas financeiras". Os autores, no 
artigo original, consideram que "pessoas com baixo nível de habilidades não cognitivas são menos propensas a planejar a aposentadoria e economizar, e têm maior propensão a comprar impulsivamente e ter dívidas inseguras" (PARISE; PEIJNENBURG, 2017, p. 6. Tradução nossa)[6].

Outro dado apontado no estudo foi que pessoas com emocional mais vulnerável tendem a realizar mais compras por impulso e contraem algum tipo de dívida sem garantia e com algum outro tipo de risco.

Já se tem falado que na maior parte do tempo as decisões financeiras são tomadas de maneira rápida e automática, considerando-se que quase sempre as pessoas deixam de analisar todas as alternativas e agem por impulso, a exemplo da conhecida experiência de se comprar um roupa ou um objeto que nunca chegou a ser usado.

Prossegue-se, neste capítulo, com a apresentação e análise dos resultados do Perfil Financeiro dos participantes da pesquisa.

\subsection{PERFIL FINANCEIRO}

Para se identificar o perfil financeiro dos participantes, aplicou-se um questionário constituído de 10 perguntas (confira-se no Quadro 4) com o propósito de avaliar características que sugerem três perfis financeiros: Endividado, equilibrado financeiramente e Investidor. 1) Endividado - que é aquele que está endividado ou muito próximo disso; 2) Equilibrado financeiramente - que é aquele para quem tudo parece estar em ordem porque não tem dívidas (se as tiver, estão controladas), contudo não criou o hábito de guardar parte do dinheiro que ganha e não consegue ter reservas financeiras; 3) Investidor - o que está no caminho certo, pois tem o hábito de poupar, de guardar parte do dinheiro que passa por suas mãos, o segredo para que um sonho se realize.

Esse questionário foi criado por Domingos (2012), professor, educador e terapeuta financeiro, autor de diversas obras sobre o tema.

RC: 102606

Link de acesso:

https://www.nucleodoconhecimento.com.br/administracao/comportamento-financeiro 
Quadro 4 - Questionário para identificação do perfil financeiro

\title{
PERFIL FINANCEIRO
}

Perguntas

O que você ganha por mês é suficiente dos para arcar com os É seus gastos?

\section{Proposições}

Consigo pagar as minhas contas e ainda guardo mais $10 \%$ meus ganhos. É suficiente, mas não sobra nada. Gasto todo meu dinheiro e ainda uso o limite do cheque especial ou peço emprestado para parentes e amigos

\begin{abstract}
Você tem Pago em dia, à vista, e, em alguns casos, com um bom conseguido pagar desconto.

suas despesas em Quase sempre, mas tenho que parcelar as compras de dia e à vista? maior valor. Sempre parcelo meus compromissos e utilizo linhas de crédito como cheque especial, cartão de crédito e crediário
\end{abstract}

Você realiza o seu Faço periodicamente e comparo o orçado com o realizado. orçamento Somente registro o realizado, sem analisar os gastos. mensalmente? Não faço o meu orçamento financeiro

Você consegue Utilizo mais de $10 \%$ do que eu ganho em linha de fazer algum tipo de investimentos, que variam de acordo com os meus sonhos. investimento? Quando sobra dinheiro, invisto normalmente na poupança. Nunca sobra dinheiro para esse tipo de ação.

RC: 102606

Link de acesso: 
Como você planeja Tenho planos alternativos de previdência privada para sua aposentadoria? garantir a minha segurança financeira. Contribuo para a previdência social. Sei que preciso de reserva extra, mas não consigo poupar. Não contribuo para a previdência social e nem para a privada.

O que você entende Que posso trabalhar por prazer e não por necessidade. sobre ser Que posso ter dinheiro para viver bem o dia a dia. independente Que posso curtir a vida intensamente e não pensar no financeiramente? futuro.

Você sabe quais são Sei quais são, quanto custam e quanto tempo terei que os seus objetivos e guardar para realizá-los. sonhos de curto, Tenho muitos sonhos e sei quanto custam, mas não sei médio e longo como realizá-los. prazos?

Não tenho sonhos, mas, se tenho, sempre acabo deixandoos para o futuro, porque não consigo guardar dinheiro para eles.

Se um imprevisto Faria um bom diagnóstico financeiro, registrando o que alterasse a sua ganho e o que gasto, além dos meus investimentos e situação financeira, dívidas, se os tiver; qual seria a sua Cortaria despesas e gastos desnecessários; reação? Não saberia por onde começar e teria medo de encarar a minha verdadeira situação financeira.

Se a partir de hoje Conseguiria fazer tudo que faço por 5, 10 ou mais anos. você não recebesse Manteria meu padrão de vida por $1 \mathrm{a}$, no máximo, 4 anos. mais seu ganho, por Não conseguiria me manter nem por alguns meses quanto tempo você conseguiria manter seu atual padrão de vida? 


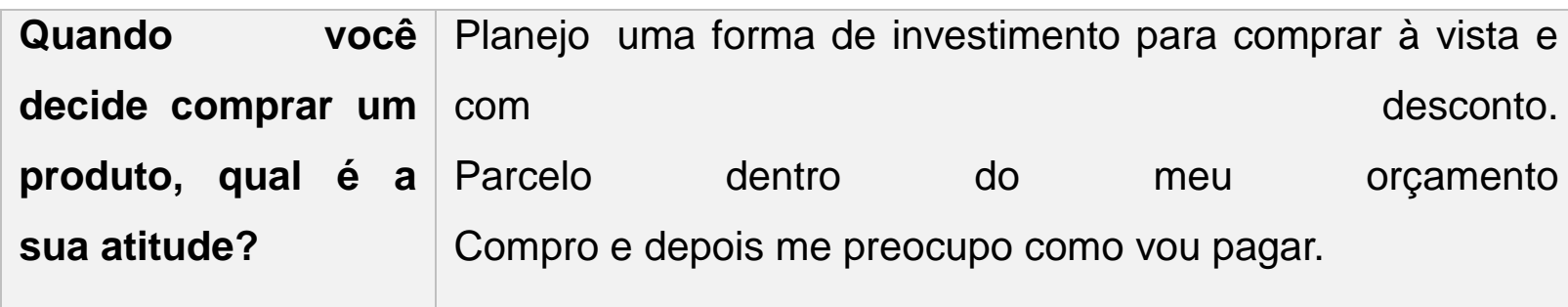

Fonte: Domingos (2012).

Cada uma dessas 10 perguntas contém três opções de respostas ( $a, b$ e c), às quais são atribuídos pesos: resposta $a=$ peso 10 ; resposta $b=$ peso 5 ; resposta $c=$ peso 0 . A pontuação final para efeito de classificação do perfil é a seguinte: e 80 a 100, perfil Investidor; de 50 a 75, perfil Equilibrado financeiramente; de 0 a 45, perfil Endividado.

Assim, seguindo esse critério, foi possível, pela frequência das respostas dos participantes às questões correspondentes ao perfil financeiro, fazer o cálculo dos pontos referentes a cada perfil. Tendo como base essas pontuações, identificou-se o perfil financeiro dos 72 participantes da pesquisa. Confira-se, pela Tabela 1, esse resultado.

Tabela 1 - Dados numéricos referentes ao perfil financeiro dos participantes

\begin{tabular}{|l|l|l|}
\hline Perfil Financeiro & Frequência & Percentual \\
\hline Investidor & 15 & $20,8 \%$ \\
\hline Equilibrado & 41 & $57 \%$ \\
\hline Endividado & 16 & $22,2 \%$ \\
\hline Total & $\mathbf{7 2}$ & $\mathbf{1 0 0} \%$ \\
\hline
\end{tabular}

Fonte: Dados da pesquisa.

Observe-se que esse resultado evidencia claramente o perfil Equilibrado (57\%), se levada em conta a pontuação dos outros dois perfis - 20,80\% para Investidor e $22,20 \%$ para endividado. Com esses resultados, identificou-se um perfil financeiro predominantemente equilibrado (57\%), que caracteriza indivíduos para os quais tudo

RC: 102606

Link de acesso:

https://www.nucleodoconhecimento.com.br/administracao/comportamento-financeiro 
parece estar em ordem porque não tem dívidas - e quando as tem, sabe controlálas.

$\mathrm{Na}$ Tabela 2, a seguir, demonstra-se a correlação dos traços de personalidade e o perfil financeiro, de acordo com os percentuais apontados nos resultados da pesquisa.

Tabela 2 - Correlação dos dados sobre o perfil financeiro e os traços de personalidade dos participantes da pesquisa

\begin{tabular}{|c|c|c|c|}
\hline Traços de Personalidade & Percentual & Perfil financeiro & Percentual \\
\hline Conscienciosidade & $62,50 \%$ & $\begin{array}{l}\text { Investidor } \\
\text { Equilibrado } \\
\text { Endividado }\end{array}$ & $\begin{array}{l}15 \% \\
43 \% \\
4 \%\end{array}$ \\
\hline $\begin{array}{lll}\text { Abertura } & \text { a } & \text { novas } \\
\text { experiências } & & \\
\end{array}$ & $23,50 \%$ & $\begin{array}{l}\text { Investidor } \\
\text { Equilibrado } \\
\text { Endividado }\end{array}$ & $\begin{array}{l}3 \% \\
9 \% \\
11 \%\end{array}$ \\
\hline Extroversão & $5,50 \%$ & $\begin{array}{l}\text { Investidor } \\
\text { Equilibrado } \\
\text { Endividado }\end{array}$ & $\begin{array}{l}0 \% \\
4 \% \\
1 \%\end{array}$ \\
\hline - & - & - & - \\
\hline Afabilidade & $5,50 \%$ & $\begin{array}{l}\text { Investidor } \\
\text { Equilibrado } \\
\text { Endividado }\end{array}$ & $\begin{array}{l}1 \% \\
3 \% \\
3 \%\end{array}$ \\
\hline Neuroticismo & $3,00 \%$ & $\begin{array}{l}\text { Investidor } \\
\text { Equilibrado } \\
\text { Endividado }\end{array}$ & $\begin{array}{l}0 \% \\
0 \% \\
3 \%\end{array}$ \\
\hline Total & $100 \%$ & & $100 \%$ \\
\hline
\end{tabular}

Fonte: dados da pesquisa 
Esses dados evidenciam o traço de personalidade Conscienciosidade como característico dos participantes, haja vista que $62,50 \%$ da amostra mostrou possuílo; desse percentual, $43 \%$ demonstraram possuir perfil financeiro equilibrado, $15 \%$, investidor e somente $4 \%$, endividado, o que ratifica, portanto, a identificação do traço Conscienciosidade. De acordo com Simões (2016, p. 9), "Conscienciosidade" "é uma dimensão que incide em questões como a responsabilidade, autodisciplina, controle de impulsos e orientação". Um nível elevado desse traço de personalidade se manifesta pela "eficiência, organização, rigor, autocontrole, respeito pelas normas, determinação e produtividade" e por meio das facetas "competência, ordem, autodisciplina, deliberação, sentido de dever, esforço de realização" (SIMÕES, 2016, p. 9).

O segundo traço de personalidade mais acentuado da amostra foi a abertura a novas experiências, com 23,5\%; o perfil financeiro identificado dentro desse traço corresponde a $11 \%$ endividado, $9 \%$ equilibrado e somente $3 \%$ investidor.

Vários comportamentos estão relacionados ao traço de personalidade "Abertura à Experiência", haja vista que os indivíduos com esse traço vivem em constante busca de novas experiências, sensações e atividades intelectuais diversas. Quando o traço Abertura à Experiência se mostra proeminente, esses indivíduos chegam a manifestar pensamentos fantasiosos, sonhadores, ou mesmo criativos e liberais, conforme observado por Simões (2016).

Em terceiro e quarto lugar, na identificação dos traços de personalidade, correspondem à Extroversão e Afabilidade, cada um deles com 5,5\% da amostra. Extroversão" é o traço de personalidade oposto à introversão. Os indivíduos extrovertidos, portanto, encaram a vida de forma positiva e se mostram "confiantes, entusiastas, enérgicos, faladores", ao contrário das pessoas introvertidas, que se caracterizam por serem tímidas, reservadas, tranquilas e, até mesmo, antissociais, uma vez que tendem a se afastar do convívio social (SIMÕES, 2016). Segundo essa autora, o indivíduo que possui o traço da extroversão costuma manifestar emoções positivas e se faz marcar pela assertividade, cordialidade e sociabilidade. 
Dessa amostra cujo traço de personalidade é extrovertido, não se identificou perfil financeiro investidor; entretanto, $4 \%$ mostraram perfil equilibrado e $1 \%$ endividado.

Com relação ao traço de personalidade neuroticismo, identificaram-se $3 \%$ dos participantes, percentual que corresponde a $100 \%$ do perfil financeiro endividado. De acordo com Simões (2016, p. 8), "o 'Neuroticismo' é um traço oposto à Estabilidade Emocional; caracteriza um indivíduo cuja tendência é "perceber a realidade como sendo ameaçadora e difícil, [...] sentir emoções negativas, ser preocupado, sensível e temperamental".

A autora ressalta que os indivíduos que apresentam nível elevado desse traço de personalidade costumam manifestar nervosismo, pessimismo e, consequentemente, baixa autoestima. Em contrapartida, as pessoas com baixo nível de Neuroticismo costumam ser calmas, otimistas e estáveis, mostrando-se, com frequência, ansiosas, impulsivas, depressivas, hostis e, portanto, vulneráveis (SIMÕES, 2016).

Conquanto não se tenha projetado, para a pesquisa, trabalhar com variáveis, considera-se válido mencionar, aqui, que $22,20 \%$ dos participantes revelaram possuir renda mensal acima de $\mathrm{R} \$ 8.640,00$ e que $62 \%$ desse percentual se identificaram dentro do traço de personalidade Conscienciosidade.

Nesse sentido, sugere-se a realização de novos estudos que levem em conta variáveis como a da renda dos participantes, tendo em vista que pode haver correlação entre os traços de personalidade e variáveis como esta.

Ao se analisarem os traços de personalidade pretende-se enriquecer o estudo sobre o comportamento financeiro das pessoas, pois o pressuposto é de que elas tendem a tomar decisões em eventos incertos, e o modelo permite analisar, inclusive, como elas processam as informações. A tomada de decisões em situações de incerteza, de acordo com Borghans et al. (2008), alarga a possibilidade de se estudar a personalidade para variáveis econômicas. 


\section{CONSIDERAÇÕES FINAIS}

Existe todo um panorama de endividamento e inadimplência que preocupa, considerando-se as consequências que ele gera na vida pessoal e familiar dos indivíduos: depressão, estresse, doenças do coração, distúrbios do sono, dentre outros problemas que limitam a vida e desestruturam a família. Nesse sentido, o conhecimento financeiro apresenta como uma ferramenta que pode minimizar o nível de dívida da população.

A economia comportamental afasta-se da ideia de que as pessoas tomam sempre as melhores decisões. Ela reconhece que as pessoas têm limite de percepção, são influenciadas por fatores emocionais e que esses fatores emocionais impactam no comportamento financeiros das pessoas.

Considerou-se, neste estudo, que cada indivíduo é único em suas particularidades, seus comportamentos não seguem o mesmo padrão dos outros, ou seja, as pessoas têm habilidades individuais que podem determinar o comportamento financeiro. Essa percepção consolidou uma teoria que recebe a denominação de traços de personalidade, cuja abordagem tem auxiliado a pesquisa sobre padrões de comportamento no âmbito social e econômico (BORGHANS et al., 2008).

Foi nessa direção que se levantou a questão direcionadora da pesquisa, qual seja: Quais os traços de personalidade que podem estar relacionados ao perfil financeiro de adultos de uma cidade do Estado do Rio de Janeiro? Desse modo, os dados evidenciam o traço de personalidade Conscienciosidade como característico dos adultos de uma cidade do estado do Rio de Janeiro, haja vista que $62,50 \%$ da amostra mostrou possuí-lo; desse percentual, 43\% demonstraram possuir perfil financeiro equilibrado, $15 \%$, investidor e somente $4 \%$, endividado, o que ratifica, portanto, a identificação do traço Conscienciosidade. Um nível elevado desse traço de personalidade se manifesta pela "eficiência, organização, rigor, autocontrole, respeito pelas normas, determinação e produtividade" e por meio das facetas 
"competência, ordem, autodisciplina, deliberação, sentido de dever, esforço de realização

Nesse mesmo contexto, o estudo identificou que o traço de personalidade Conscienciosidade está relacionado ao perfil financeiro equilibrado de adultos de uma cidade do Estado do Rio de Janeiro. Esse resultado contempla o objetivo geral do estudo de correlacionar as características predominantes dos traços de personalidade com o perfil financeiro dos indivíduos, com base na leitura e interpretação dos resultados, e até mesmo das inferências que se divisaram por trás dos dados, pôde-se evidenciar essa correção.

Com este estudo, não se considera o tema esgotado, ao contrário, vislumbra a necessidade de novos estudos que se debrucem sobre ele e delineiem outros resultados desta e de outras pesquisas, com o objetivo de expandir o tema, os dados do estudo, além de estabelecer variáveis que permitam resultados ainda mais efetivos.

\section{REFERÊNCIAS}

ARIELY, Dan; KREISLER, Jeff. A psicologia do dinheiro: Descubra como as emoções influenciam nossas escolhas financeiras e aprenda a tomar decisões mais inteligentes. Rio de janeiro: Sextante, 2019.

ÁVILA, Flávia; BIANCHI, Ana Maria. Economia Comportamental: Como e Quando Surgiu? (s.n.). Disponível em: http://www.economiacomportamental.org/como-equando-surgiu/. Acesso em: 26 mar. 2020.

BORGHANS, Lex; DUCKWORTH, Angela Lee; HECKMAN, James; WEEL, Baster. The economics and psychology of personality traits. Journal of human Resources, v. 43, n. 4, p. 972-1059, 2008. 
CAMERER, Colin Farrell. Behavioral economics: Reunifying psychology and economics. Proc. Natl. Acad. Sci. USA, Vol. 96, pp. 10575-10577, September 1999.

CAMERER, Colin Farrell. Behavioral Economics. World Congress of the Econometric Society, London, 18-24 August 2005.

DOMINGOS, Reinaldo. Terapia financeira: realize seus sonhos com educação financeira. São Paulo: DSOP Eduacação Financeira, 2012.

DSOP EDUCAÇÃO FINANCEIRA. O que é Educação Financeira? Disponível em: https://www.dsop.com.br. Acesso em: 21 mar. 2020.

EDIT, A. G. Habilidades não cognitivas podem afetar decisões financeiras? 16 de fevereiro de 2018.2 Disponível em: https://pensologoinvisto.cvm.gov.br/habilidades-nao-cognitivas-podem-afetardecisoes-financeiras/\#more-1821. Acesso em: 23 jun. 2020.

EHLKE, Rafaella. Conheça mais sobre a teoria dos traços de personalidade e em qual você se encaixa. 25/6/2019. Disponível em: https://www.institutolifecoaching.com.br/blog/desenvolvimento-pessoal/teoria-dostracos-de-personalidade/. Acesso em: 25 maio 2020.

FERREIRA, vera Rita de Mello. Educação Financeira e Psicologia Econômica - uma discussão e algumas recomendações. FGV EAESP - GVcef - 2o Encontro Brasileiro de Economia e Finanças Comportamentais, 2015. Disponível em: https://bibliotecadigital.fgv.br/dspace/handle/10438/18872. Acesso em: 21 ago. 2020.

IDRLABS. Individual Differences Research. Teste dos cinco grandes fatores (versão curta). 2020. Disponível em: https://www.idrlabs.com/pt/cinco-grandesversao-curta/teste.php. Acesso em: 25 set. 2020. 
KAHNEMAN, Daniel; TVERSKY, Amos. Prospect Theory: An Analysis of Decision under Risk. Econometrica, 47(2), 1979, 263-291.

LIKERT, Rensis. A Technique for the Measurement of Attitudes. Archives of Psychology, v. 22, n. 140, p 55.5, 1932.

MELO, Nara. Pesquisa sobre educação Financeira e Fatores de Personalidade. 23 de julho de 2015. Disponível em: http://pensologoinvisto.cvm.gov.br/pesquisasobre-educacao-financeira-e-fatores-de-personalidade/. Acesso em: 19 set. 2019.

MILANEZ, Daniel Yabe. Finanças comportamentais no Brasil. 2003. 53f. Dissertação (Mestrado em Economia das Instituições e do Desenvolvimento) Faculdade de Economia, Administração e Contabilidade, Universidade de São Paulo, São Paulo, 2003.

MINAYO, Maria Cecília de Souza. (Org.). Pesquisa Social. Teoria, método e criatividade. 18. ed. Petrópolis: Vozes, 2001.

NUNES, Bernardo Fonseca. Educação Financeira, fatores Psicológicos e Comportamento Financeiro. Behavioural Science Centre, University of Stirling, 2016.

PACHECO, Greicy Bainha. Atitude ao endividamento, personalidade e conhecimento financeiro: um estudo com os servidores da Universidade Federal de Santa Catarina. 2017. 131f. Dissertação (mestrado) Programa de PósGraduação em Administração. Centro Sócio-Econômico, Universidade Federal de Santa Catarina-UFSC, Florianópolis, SC, 2017.

PACHECO, Greicy Bainha; CAMPARA, Jéssica Pulino; COSTA JR., Newton Carneiro Affonso. Traços de personalidade, atitude ao endividamento e conhecimento financeiro: um retrato dos servidores da Universidade Federal de Santa Catarina. Revista de Ciências da Administração, v. 20, n. 52, p. 54-73, Dezembro, 2018. 
PARISE, Gianpaolo; PEIJNENBURG, Kim. Understanding the determinants of financial outcomes and choices: the role of noncognitive abilities. Bank for International Settlements. Monetary and Economic Department. May 2017.

SCHULTZ, Duane; SCHULTZ, Sidney Ellen. Teoria da Personalidade. 3. ed. SP: Editora Cengage Learning, 2016.

SIMÕES, Vanessa Jesus. Adaptação e Validação do teste de personalidade MinilPIP e Big Five Inventory (BFI) em adultos portugueses. 2016. 66f. Dissertação (Mestrado) - Psicologia da Educação, Desenvolvimento e Aconselhamento). Universidade de Coimbra - Faculdade de Psicologia e de Ciências da Educação UC/FPCE. 2016.

SIMON, Herbert Alexander. Administrative behavior: a study of decision - making processes in Administrative Organization, 1st ed., New York: The Macmillian Company, 1947.

SILVA, Isabela Brito; NAKANO, Tatiana de Cassia. Modelo dos cinco grandes fatores da personalidade: análise de pesquisas. Avaliação Psicológica, Porto Alegre, v. 10, n. 1, p. 51-62, abr. 2011.

SURVIO. Pesquisa online. Disponível em Acesse: http://www.survio.com/br/

YOSHINAGA, Claudia Emiko; OLIVEIRA, Raquel Freitas de; SILVEIRA, Alexandre Di Miceli da; BARROS, Lucas Ayres Barreira de. Finanças comportamentais: uma introdução. Revista de Gestão USP, v. 15, p. 25-35, jul-set, 2008.

\section{APÊNDICE - REFERÊNCIA NOTA DE RODAPÉ}

3. A metodologia DSOP é um recurso de educação financeira que foi criado por Reinaldo Domingos. A metodologia é composta de quatro pilares, são eles: Diagnosticar, Sonhar Orçar e Poupar que, de uma maneira simples, ajuda a conduzir uma pessoa a realização de todos os seus sonhos. 
4. Flávia Ávila e Ana Maria Bianchi fazem parte de um grupo de pesquisadores sobre o tema Economia Comportamental, que mantêm um site de onde foram retirados os textos citados. Disponível em: http://www.economiacomportamental.org/como-e-quando-surgiu/.

\section{EDIT_AG. Habilidades não cognitivas podem afetar decisões financeiras? 16} de fevereiro de 2018.2 Disponível em: https://pensologoinvisto.cvm.gov.br/habilidades-nao-cognitivas-podem-afetardecisoes-financeiras/\#more-1821. Acesso em: 23 jun. 2020.

6. "Noncognitives abilities influence financial choices". "Namely, people with lower abilities are less likely to plan for retirement and save, and have a higher propensity to buy impulsively and to have unsecured debt".

Enviado: Novembro, 2021.

Aprovado: Dezembro, 2021. 